$$
\zeta \overline{=}
$$




\section{Empatía y ética animal}

\section{Introducción}

Al principio este trabajo iba a tratar sobre por qué el antropocentrismo es un problema irrelevante para las discusiones de bioética y deberíamos prescindir de él. El argumento era que sostener una actitud antropocéntrica, tanto moderada como dura, tenía las mismas consecuencias a nivel práctico. Un antropocentrista apelará a la utilidad del medio ambiente y de las especies que en él habitan para la vida humana; y por ello sería importante que cuidara del ecosistema para mantener dichos beneficios. Por otro lado, un no antropocentrista apelará a que los animales y el ecosistema cuentan con una suerte de valor intrínseco y deberíamos cuidarlos atendiendo a dicho valor. Es por ello que las distinciones sólo podrían verse a un nivel teórico.

$\mathrm{El}$ argumento es débil, un antropocentrista bien podría creer en la utilidad de la naturaleza y sus beneficios, pero esto no implica que deba cuidarlos. Además, ¿̇es realmente el antropocentrismo un problema actual? No parece. Sabemos, gracias a los estudios en biología, que las especies actuales, incluidos los seres humanos, son el resultado de un proceso azaroso en el que algunas han sido capaces de adaptarse mejor que otras y, por esta razón, sobrevivir; al ser los seres humanos parte de dicho proceso, no parece haber una verdadera distinción. Sin embargo, alguien podría sostener que los estudios de Darwin son erróneos y que de hecho el ser humano tuvo un proceso especial, por ejemplo, que fue creado a imagen y semejanza de Dios. Dicha creencia puede ser respetable, pero no por ello verdadera. Creo, sin embargo, que en una sociedad moderna es mejor la búsqueda de una ética secularizada, ya que eso nos ayudaría a dar cuenta de las acciones tanto de los creyentes como de los agnósticos.

Otra cuestión por la que creo que muy pocos sostendrían actualmente una forma de antropocentrismo fuerte es que no vemos a los seres vivos no humanos como si fuesen máquinas o una suerte 
de autómatas incapaces de sentir dolor. Es por demás sabido que los animales son capaces de sentir dolor y por ello existe cierto grado de empatía. Por eso creo que es deseable una ética del bienestar animal.

Además, creo que el problema ha dejado de ser que un punto de vista antropocéntrico sea el común dentro de una comunidad. Ahora somos capaces de aceptar que debemos cierto respeto hacia las especies ajenas a la nuestra. Sin embargo, de esta relación de respeto se ha querido concluir que las especies no humanas son entidades morales, lo que ha llevado la discusión a un punto opuesto. Ya no se es antropocentrista duro, sino que algunos han pasado a creer que los animales deberían tener una carta de derechos al igual que la tienen los humanos ${ }^{1}$. Desde que los animales pueden entrar dentro del contrato social, entonces pueden ser susceptibles de derechos y obligaciones.

Sigo creyendo que el problema del antropocentrismo es irrelevante, pero no por la supuesta igualdad práctica, sino porque no creo que sea un problema genuino. Quizá cuando iniciaron las discusiones sobre bioética o cuando se sostenía una moral religiosa, dicho problema era una parte central de las discusiones, ya que se requería explicar por qué es legítimo otorgar nuestra empatía ${ }^{2}$ a las especies ajenas. Es por ello que argumentaré, en este trabajo, sobre por qué sería bueno dejar los animales fuera del Estado de derecho $y$, aun así, brindarles cierto respeto.

Me gustaría defender en este trabajo que es difícil mantener una postura que incluya a los animales en el contrato social. Sin embargo, esto no significa tirar por la borda una ética que incluya a las especies no humanas. Creo que la empatía que pueden tener los seres humanos puede extenderse a las diferentes especies. La empatía es una buena forma de mantener un respeto hacia los animales.

1 Esto parece ser lo que sostienen algunos utilitaristas modernos que defienden los derechos animales. Vid. Singer, P., Animal Liberation, Harper Collins Publisher, New York, 2002.

2 Empatía, en este trabajo, será utilizado de forma más o menos intuitiva. Aquello que regularmente pensamos que es la empatía: algo así como "ponerse en los zapatos del otro". Esto ciertamente es un punto débil del argumento. Si el lector quiere encontrar información más detallada sobre la empatía, me gustaría dirigirlo al artículo de Heidi L. Maibom titulado "Almost Everything you ever wanted to know about Empathy" (en H. L. Ed., Empathy and Morality, Oxford University Press, New York, 2014, pp. 1-40). 
Esta postura, aunque no habla sobre empatía propiamente, sino de sentimentalismo, parece ser una que Rorty defiende en su texto "Derechos humanos, racionalidad y sentimentalismo" ${ }^{\prime \prime}$. El argumento de Rorty parte de que toda forma de derechos humanos se basa en la concepción que se tenga de bumano. Así:

La distinción humano/animal, sin embargo, es sólo uno de los tres modos principales en los cuales, nosotros, los humanos paradigmáticos, nos distinguimos de los casos limítrofes. Un segundo modo consiste en la invocación de la distinción entre adultos y niños. Las personas ignorantes y supersticiosas, decimos, son como los niños; alcanzarán la verdadera humanidad sólo si son criadas de acuerdo con una educación apropiada. Si parecen incapaces de tal crianza, eso demuestra que no pertenecen realmente al mismo tipo de ser que nosotros, las personas educables. Los negros, solían decir los blancos de los Estados Unidos y de África del Sur, son como los niños; por eso es apropiado llamar a un negro, cualquiera que sea su edad, "chico". Las mujeres, solían decir los hombres, son perpetuamente infantiles; por eso no conviene gastar dinero en su educación y sí conviene negarles el acceso al poder. ${ }^{4}$

Rorty parece sostener en dicho artículo que para poder predicar derechos de diferentes clases de hombres, debemos partir de una concepción de hombre. Concepción que tendría que ser una definición real que incluyera a hombres y sólo a los hombres ${ }^{5}$, quienes podrían ser entidades morales con derechos propios. Según Rorty, dicha definición no puede darse, pues cualquier intento de ella dejará fuera a algunos o a otros que regularmente llamamos hombres, y aun, si se diera, todavía dejaría de lado a las distintas especies: "En particular, defenderé mi afirmación de que nada que atañe a la elección moral separa a los seres humanos de los animales, salvo hechos del mundo históricamente contingentes, es decir, hechos culturales."

3 Rorty, R, Derechos humanos, racionalidad y sentimentalismo, en R. Rorty, Verdad y progreso, Ed. Paidós, España.

4 Ibidem p. 3.

5 Para no confundir, cuando se dice hombre se está refiriendo a toda la clase de los seres humanos.

6 Rorty, R. op. cit., p. 5. 
A diferencia de Rorty, creo que aunque dicha definición no se haya logrado, eso no significa que la misma no exista. Sin embargo, el problema de cómo tratemos a los humanos y a los animales, puede resolverse momentáneamente apelando a la empatía. Un rasgo de los seres humanos es que somos capaces de ser empáticos no sólo entre nuestra especie, sino con todas las del reino animal.

La empatía, sostengo, ayudaría a sostener una ética no antropocentrista y, aun así, mantener a los animales fuera del Estado de derecho. Esta estrategia nos permitirá conservar cierto grado de respeto hacia las otras especies, sin considerar que comer su carne es un asesinato. Sin embargo, esta estrategia también ignora el problema de si los animales son susceptibles o no de tener derechos. Mi propósito es más humilde que eso. Si queremos mantener un respeto a los animales, y dejarlos fuera del Estado de derecho, una forma de hacerlo es apelando a la empatía.

Ahora, ¿es deseable predicar propiedades morales de los animales? El ser humano es una especie (Homo sapiens) del género de los primates. Somos, en algún sentido, una especie privilegiada. Pero la pertenencia a una especie no explica por qué los seres humanos somos considerados entidades morales y por qué dicha categoría no se aplica a distintas especies. Una forma en la que se procede a incluir a otras especies dentro de la categoría de personas morales sería optar por definir lo que significa que algo sea una entidad moral ${ }^{7}$. Para ello, tendríamos que encontrar condiciones definitorias que den cuenta de este fenómeno ${ }^{8}$. No obstante, después de haber hecho una definición exhaustiva, es posible que encontremos que la definición ha sido demasiado abierta (por ejemplo, si incluye a los seres vivos de todos los reinos) o demasiado limitada

7 Tristan Engelhardt, en su libro Los fundamentos de la bioética, procede con este espíritu definitorio respecto a la distinción humano/persona. Donde "humano" se aplica a toda la especie Homo sapiens de forma indiscriminada, mientras que "persona" se aplica a aquellos seres con conciencia propia, racionales y que son agentes morales.

8 Algunos de los rasgos para que algo sea una entidad moral podrían ser la capacidad de pensar de forma abstracta, sentir compasión, ser capaces de utilizar lenguaje, etc. Aunque esta discusión no esté cerrada de una vez por todas, parece que se acepta que si un juez dictamina que un único animal es susceptible de tener derechos gracias a su parecido con la especie humana, entonces se convierte en una entidad moral con derechos propios. 
(por ejemplo, si incluye sólo a la orden de los primates). Además, una definición rigurosa de este tipo no podría hacerse con nuestros conocimientos actuales. Aún no conocemos todos los aspectos cognitivos de las especies no humanas y los avances en neurología muestran que dichas especies son capaces de hacer actividades que se pensaban propias del ser humano.

No parece, entonces, haber una buena razón para creer que los animales no deberían merecer algún grado de respeto. Compartimos más rasgos de los que se pensaba originalmente. Aun así, una razón positiva sería un buen elemento para hacer más fuerte el argumento. Una razón provisional, al menos, podría apelar a la reducción de violencia. La caza inmoderada es una de las formas que hay para extinguir a la gran variedad de especies que ha dado la selección natural. Creo que es importante reducir el grado de violencia con que se mata a los animales, además de la caza inmoderada de la que a veces son víctimas.

Pero también es importante excluirlos del Estado de derecho. Además, aceptar una distinción de grado implica que las propiedades predicadas de los seres humanos, también deberían, en algún grado, ser predicadas de otras especies. Esto ha llevado a algunos a sostener que los animales deberían pertenecer al Estado de derecho. Por ejemplo, Steven Wise ereó el "proyecto de los animales no-humanos", que busca otorgar a los animales protección legal, apelando a una cláusula que señala que si algo comparte propiedades relevantes de un ser humano, entonces debería ser tratado como tal. El argumento es que existe una distinción entre "cosas legales" y "personas legales"; los animales han sido tratados como cosas legales, cuando deberían ser tratados como personas legales. Las cosas legales son pertenencias y si alguien es dueño, por ejemplo de un terreno, puede venderlo, rentarlo o hacer con él lo que más le convenga. Dado que es una cosa legal, y en este sentido es propiedad privada, el dueño tiene esta libertad de actuar. Sin embargo, las personas legales no pueden ser pertenencias. Wise pretende cambiar el estatus de los animales de cosas legales a personas legales. Una cosa legal puede convertirse en una persona legal si comparte las propiedades necesarias para ser lo suficientemente parecido a un ser humano, y dado que los animales tienen algunas

9 Para encontrar información acerca de su proyecto puede visitarse su página web. El link se encuentra en las referencias. 
propiedades que de hecho se parecen a las del ser humano, pueden ser declarados personas legales si un juez así lo dictamina ${ }^{10}$.

El trabajo de Wise es legítimo, tiene razones para llevarlo a cabo. Pero, respondiendo a Wise, si los animales se vuelven susceptibles de derechos, entones nosotros les debemos obligaciones, estamos obligados a respetar sus derechos. Además, las especies no humanas están obligadas a respetar nuestros derechos y los derechos de otros animales. Por un lado, esto lleva a que algunas de las prácticas comunes, como la de tener un perro, podría llegar a exigir trámites burocráticos tediosos e innecesarios. Tendríamos primero que pedir el consentimiento del perro para que pueda entonces ser adoptado y, dada su falta de poder comunicativo, se volvería un proceso difícil. No obstante, esto podría solucionarse apelando a que tendrían que existir tutores que intercedieran por las especies no humanas, otro trámite que sería innecesario. Pero además, muchas de las prácticas que involucran a los animales - por ejemplo cuando se prueba un medicamento o cuando se buscan especies animales para investigar aspectos de los seres humanos-, tendrían que dejar de llevarse a cabo porque violarían un derecho; dicho sea de paso, se trata de investigaciones de las que depende, algunas veces, nuestro bienestar, otras, nuestra propia comprensión anatómica. Como dice Scruton: "When a dog savages a sheep no one believes that the dog, rather than its owner, should be sued for damages." $\mathrm{El}$ problema de que los animales son vistos como cosas legales o simplemente como instrumento, por un lado, y el problema de que pertenezcan al Estado de derecho, por otro, podrían solucionarse apelando a nuestra capacidad empática, lo que llevaría a un trato correcto. No intento decir que no deban ser utilizados para experimentación, sino que deberían ser utilizados bajo condiciones adecuadas. Importa más, a mi parecer, el cómo y cuándo son utilizados. Además de estar adecuadamente justificado su uso en una situación dada.

10 Por ejemplo si se priva, en contra de su voluntad, la libertad a una persona legal, se está cayendo en un delito. Algo que ocurre muy seguido con animales, que son privados de manera ilícita de su libertad.

11 "Cuando un perro violenta a una oveja, nadie creería que el perro, más que su dueño, deba ser demandado por los daños". Vid. Scruton, R., Animal Rights and Wrongs, Bloombsbury, London, 2006, p. 60 . 
Lo que trato de decir es lo siguiente: el ser humano es una especie capaz de sentir empatía y extenderla a otras especies muy diversas. Aprovecharnos de esta empatía nos permite respetar a las especies ajenas. Creo que para poder iniciar una cultura de la empatía animal, es necesaria la divulgación de ciencias como la biología y la etología, e iniciar una educación referente a estos temas. De esta manera, podría abandonarse una posición antropocentrista y también así su opuesto diametral. 